\title{
América en el pensamiento de don Miguel de Unamuno: El binomio Bolívar-Unamuno
}

Felipe Callero

UNED

Resumen:

El polifacético Unamuno tuvo una dimensión importantísima de su vida intelectual, y ésta fue América. Se convirtió en maestro de muchos autores hispanoamericanos, además de ser habitual corresponsal de los periódicos y revistas de esa parte del mundo; al cartearse con la mayoría de sus coetáneos y con un sinfín de autores (epistolomanía) que buscaban su consejo. Pero además supo extender su quijotismo, con una dedicación especial a Bolívar: el gran majadero, a quien considera de la estirpe de Don Quijote.

Palabras Clave: América y Unamuno, Hispano-América, americanidad, epistolomanía, hispanidad, Don Quijote, Bolívar, majadero.

\section{Abstract:}

The multifaceted Unamuno had a great interest in the issues of Spanish America. He became a master of many authors of that part of the world, wrote in the outstanding papers and magazines of that time and, due to his "epistolomania", he had important relationship with people of that area who looked for his advice. That is why someone has said that "it is impossible to understand Unamuno without Spanish America". So, the aim of this article is to try to identify this special side of Unamuno, particularly for his commitment to Bolivar.

KEYWORDS: America and Unamuno, americanism, Spanish America, 'epistolomania', hispanidad, Don Quijote, Bolivar, "majadero". 


\section{Una dimensión especial de don Miguel de Unamuno: Hispanoamérica}

El conocimiento general que se tiene de don Miguel de Unamuno, intelectualmente hablando, es el que ofreciera en su momento Savater $^{1}$, cuando lo definió como "el escritor total, el escritor metido a ensayista, poeta, novelista, dramaturgo, político, místico, hereje... Un metomentodo... " A eso habría que añadir, de forma necesaria, su faceta indiscutible de filósofo. Pero se olvida con frecuencia una vertiente importante, y no es otra que su dimensión americana. No en vano algún autor ha señalado que "para comprender a Unamuno hay que leerlo en función de la América Hispana”. Lo que él mismo se encarga de reafirmar cuando en una carta reconoce que: "cada día me interesa más América y me vuelvo más hacia ella. Y ha sido para mí una salvación". ${ }^{3} Y$ así fue tejiendo una red de relaciones que mantuvo hasta su muerte. América se convirtió en una realidad cotidiana. Con gente de allá se carteaba, escribía prólogos de sus novelas, aconsejaba literariamente, discutía de forma apasionada, escribía en periódicos y revistas, con lo que, además, obtenía un sustento para él y su larga familia. Y no debemos olvidar que el vasco estudió y escribió sobre los grandes personajes hispanoamericanos históricos, tales como Bolívar, por el que sintió una predilección especial y al que llegó a emparejar con Don Quijote, y con el que acaba teniendo compartidas afinidades; Sarmiento, Montalvo, José Martí, Rubén Darío, Rodó, Nervo, etcétera. O sea, América, a la que nunca visitó, se convirtió en parte esencial de su vida.

\section{Antecedentes}

Pero ese sentimiento americano no le vino del cielo. Dos elementos debemos tener en cuenta a este respecto. El primero, su pertenencia

1 Fernando Savater. Prólogo a Del sentimiento trágico de la vida. España: Biblioteca Unamuno, Alianza Editorial, 86, 2008.

2 Gustavo Baquero. La América de Unamuno. España: Biblioteca Virtual Cervantes, 2010.

3 Carta a Manuel Ugarte. 6-3-1905, no 74 en Epistolario Americano. España: Ediciones Universidad Salamanca, 17, 1996. 
a la Generación del 98, de la que fue uno de sus más importantes exponentes. Sabido es que un elemento aglutinador de la llamada Generación del 98 fue la pérdida de las colonias americanas, no siendo extraño que los intelectuales que conformaban ese grupo tuvieran una vertiente "americana". Mas como afirmó el profesor Morales Padrón: ${ }^{4}$

La Generación del 98 no descubrió el tema americano. Los que le tratan lo reciben en herencia de la generación anterior (Menéndez Pelayo y Juan Valera)... Juan Valera, con sus "Cartas Americanas", fue un precedente de la actitud del propio Unamuno..., afirmando a renglón seguido que 'Valera y Menéndez Pelayo fueron los descubridores intelectuales de América'.

Y curiosamente, ambos autores formaron parte del Tribunal académico que examinó a Unamuno para la cátedra de griego de la Universidad de Salamanca.

A esos antecedentes, y éste sería el segundo elemento, habría que añadir su condición de hijo de un indiano, lo que él mismo cuenta, al decir que:

La mecha del fuego hispanoamericano le empezó a arder en su niñez, y le vino de su padre, un indiano que salió jovencito de Vergara, su pueblo natal, y se fue a Méjico en busca de fortuna. Así es como mi padre me trajo de esa tierra en que aprendió a trabajar y a vivir, una fuente de extraña poesía, y así es como las raíces de mi visión de Méjico se entrelazaban con las raíces de mis primeros ensueños. ${ }^{6}$

4 Francisco Morales Padrón. "La imagen de Hispanoamérica en la España de los siglos XIX y XX” en Estudios Latinoamericanos, 6, 1980, p. 1.

5 También las Nuevas Cartas Americanas. Por su parte, Menéndez Pelayo publicó primero Antología de poetas hispanoamericanos (1893-1895), más tarde mejorada y publicada como Historia de la poesía hispanoamericana (1911-1913).

6 "Mi primera visión de Méjico" en Revista Moderna de México. 14 de febrero de 1907. 


\title{
III. La importancia de Unamuno en Hispanoamérica
}

\author{
Para Morales Padrón,
}

ninguno de los representantes de la denominada Generación del 98 abarcó al mundo hispánico como Don Miguel de Unamuno... Correspondió a Unamuno definir el concepto de HISPANIDAD frente al de Latinidad. ${ }^{7}$ Con el vocablo "hispanidad", Don Miguel designaba a la comunidad de pueblos que hablan español... La base de la Hispanidad estaba en la lengua, patrimonio de todos y en la historia común. Unamuno tocó múltiples temas culturales de Hispanoamérica. La Historia americana la ve en función del quijotismo; de ahí la exaltación de Bolívar. ${ }^{8}$

Muerto el padre indiano, cuando él tenía seis años, su herencia fue una modesta biblioteca y

no pocos objetos que recordaban a aquel Méjico lejano donde pasó su juventud, y de que oía ya hablar a menudo en casa... Así es como mi padre me trajo de esa tierra en que aprendió a trabajar y a vivir, una fuente de extraña poesía, y así es como las raíces de mi visión de Méjico se entrelazaban con las raíces de mis primeros ensueños.

7 La primera vez fue en el artículo "Lecciones de Historia Americana-Sobre la argentinidad" en La Nación. Buenos Aires: 11 de marzo, 1910: "En mi correspondencia anterior, primera de las que dedico al libro de Ricardo Rojas, La restauración nacionalista, libro henchido de sugestiones, usé de dos palabras que ignoro si han sido o no usadas ya, pero que ciertamente no corren mucho. Son las palabras "americanidad" y "argentinidad". Ya otras veces he usado la de "españolidad" y la de "hispanidad". Y los italianos emplean bastante la voz "italianita". Otra vez fue en 1927 en el artículo "Hispanidad" en Síntesis, Buenos Aires: noviembre, 1927. En este artículo Unamuno vuelve sobre el concepto HISPANIDAD y no Españolidad: como concepto espiritual "para incluir a todos los linajes, a todas las razas espirituales, a las que ha hecho el alma terrena — terrosa sería mejor- - y a la vez celeste de Hispania, de Hesperia, de la Península del Sol Poniente, entre ellos a nuestros orientales hispánicos..."

8 Revista Española, año 1, no 1, 5 de marzo de 1894. 
Y entre los libros heredados del padre había una España pintores$c a$, editada en Méjico, "en cuyos grabados apacenté mis ojos ávidos de curiosidades". Y también libros de poetas mejicanos, románticos todos. "Y había, sobre todo, un ejemplar de la Historia antigua de Méjico, del P. Clavigero, empastado, aunque a la moderna, en pergamino. Y siendo un muchacho de doce años me engolfé en su lectura".

La mecha ya estaba prendida. El primer fogonazo vendría a brotar en 1894, con su primer artículo americanista: "El gaucho Martín Fierro. Poema popular gauchesco de Don José Hernández", dedicado a don Juan Valera: alabanza a esa obra de José Hernández, el Martín Fierro, conocido como el Quijote nacional. Al quejarse de lo poco conocida en España pese a su españolidad, dice de Martín Fierro: "Martín Fierro, poema de un Hernández, hijo de un Hernando español, es español hasta el tuétano", con ello se opone a que Martín Fierro "pertenezca a una literatura privativamente argentina". Se trata, sostiene de forma vehemente, "de literatura española". Con ese artículo, Unamuno se convierte en el primer escritor de habla española que "analizó extensamente el poema de José Hernández".

Y de aquel Méjico grita que debe ser, claro, Méjico y no México como algunos pedantes mejicanos se empeñaban en sostener, y es que "ahora han dado nuestros periódicos por rendirse a la pedantesca manía mejicana de escribir México, y no hay quien lo evite". Pero, claro, "por la misma razón habría que escribir Guadalaxara, Xerez, dixo, xefe, etcétera. No se ve qué privilegio ha de tener México para adoptar en él una ortografía pseudo-etimológica, cuando en castellano domina la fonética "10. Según parece no se le hizo mucho caso, ya que al final se ha impuesto la 'x'. En 1910 en 'Las Lecciones de historia americana" "ll llega a afirmar con rotundidad haber inventado las palabras "americanidad", "argentinidad" e "hispanidad". Y reconoce, sin falsa modestia, ser "uno de los poquísimos europeos que se han interesado por el conocimiento de las cosas

9 Antonio Pagés Larraya. Unamuno y la valoración crítica del "Martín Fierro". Actas del IV Congreso Internacional de Hispanistas, Vol. 2, 1982.

10 "Méjico y no México" en Madrid Cómico, 28 de mayo, 1898. Obras Completas, IV.

11 La Nación. Buenos Aires: 11 de marzo de 1910. 
de América". De 1915 data "De relaciones hispano-americanas" 12 , donde se autodenomina escritor insistente, haciendo hincapié en esas relaciones pero no como entre el padre y sus hijos, sino entre hermanos. Unamuno disiente del paternalismo español al insistir en relaciones fraternales. "La fiesta de la Raza"13 es el primero de otros artículos futuros en los que pondría el acento en una unión espiritual, cuya base fundamental es la lengua.

Su relación con Hispanoamérica fue constante y fluida, con base en sus colaboraciones en periódicos y revistas allende el Atlántico. ${ }^{14}$ Pero también las desarrolla Unamuno a través de lo que Claudio Maíz ${ }^{15}$ llama epistolomanía (aquí también debemos recordar el antecedente de Valera con sus "Cartas Americanas" y "Nuevas Cartas Americanas"), es decir, relaciones epistolares, entre las que se contabilizan: 143 argentinas; 6 bolivianas; 74 chilenas; 26 mejicanas ${ }^{16} ; 33$ venezolanas; 20 uruguayas; 35 colombianas; 18 peruanas; 6 dominicanas; 4 ecuatorianas ${ }^{17}$; 9 cubanas; 2 costarricenses; 2 salvadoreñas y 2 nicaragüenses. Las mismas cuentas saca Julio César Chaves, quien habla de corresponsales americanos de Unamuno al exclamar que “¡Con casi 400 americanos se escribía Don Miguel!”18 Y habla el

12 La Nación. Buenos Aires: 16 de enero de 1916.

13 La Nación. Buenos Aires: 29 de noviembre de 1919, FMU, CMU. 6-159.

14 "Con la Argentina, particularmente a lo largo de varios decenios — nos dice Guillermo de Torre-, mantuvo un contacto muy frecuente, merced a sus artículos en La Nación, y más de una vez pensó en llegarse a este país; estuvo a punto de hacerlo en 1916... Después, en diciembre de 1922, anunciaba en una carta a Jiménez Ilundain, su viaje inminente..." Por otro lado, nos sigue diciendo, "supera el centenar los artículos... consagrados por Unamuno a libros, temas y figuras de América.

15 Claudio Maíz. De París a Salamanca. Salamanca: Ediciones Universidad, 25, 2004, p. 63.

16 Como veremos más adelante, la autora Gemma Gordo Piñar, en su tesis Doctoral, Miguel de Unamuno y México. Relación y recepción, 2013, Madrid, habla de 72 corresponsales mejicanos, ocupando, por tanto, Méjico el tercer lugar en volumen de relaciones epistolares entre todos los países hispanoamericanos con Unamuno o viceversa.

17 Por datos recabados y obtenidos de la Biblioteca Casa Museo Unamuno, Salamanca, podemos llegar a hablar de, por lo menos, 9 corresponsales ecuatorianos.

18 J. C. Chaves. Unamuno y América. 1964. 
citado Maíz de lo que él denomina "la conexión española-americana: Unamuno-Ugarte", al cuantificar las cartas de Manuel Ugarte a Unamuno en 25 y en 10 las dirigidas por Unamuno a Ugarte, éstas durante un periodo de 20 años (la primera del 9 de julio de 1900, la última del 21 de julio de 1920). Y añade que "a través del conjunto de cartas circula un número importante de problemas literarios, sobre todo los referidos al modernismo y a la 'galofilia' hispanoamericana". ${ }^{19}$

Con todo, se observa que el maestro bilbaíno se convirtió en un modelo para los escritores hispanoamericanos, noveles sobre todo. Y así, aquellos escritores, a juicio del referido Maíz, ven en Unamuno: 1) el crítico de la literatura hispanoamericana; 2) el promotor de su propia obra; 3) predicador de ideas; y 4) el íntimo y confidente. ${ }^{20}$ Pero sin olvidarnos, y esto es en suma meritorio, que Unamuno no utilizaba distinto lenguaje en España que en Hispanoamérica: él era el mismo aquí que allá.

Habla en La Nación (o en Caras y Caretas y tantos otros periódicos hispanoamericanos) de lo mismo que habla en España, siempre con el propósito de ejercer con su pluma lo que él entiende como su labor educativa. No se dirige como maestro ilustrado que quiere enseñar a los lectores americanos con aire prepotente. En absoluto, adopta el tono crítico e irónico típico suyo. Y lo que sí se nota es que entiende el mundo americano de habla española como parte de una comunidad que comparte muchos valores y muchos defectos, una comunidad lingüística. ${ }^{21}$

Orringer ${ }^{22}$ abunda en ese aspecto: "por sus escritos, Miguel de Unamuno merece carta de ciudadanía en ambas orillas del Atlántico. Su hispanoamericanismo ha generado valiosos estudios de América en su vida y obras." ${ }^{23}$

19 Claudio Maíz, op. cit, pp. 63-65.

20 Ibidem, p. 63.

21 Pedro Rivas. "Unamuno: Su visión de América" en Formas de Hispanidad, CEPI, 2011.

${ }^{22}$ Nelson R. Orringer. Presentación, Unamuno y la "Americanidad”. Univ. de Conecticut: Colección "La Expresión Americana”, no 24, 2002.

23 "En 1870, a los seis años, con curiosidad y recelo, el niño Miguel escuchó a 
Y entonces vemos que esa relación con América se tejió: ${ }^{24}$ a través de amistades personales, bien sea en contactos directos, bien mediante cartas; colaboraciones en periódicos y revistas hispanoamericanas, así como crítico de literatura.

El primer punto lo constituye su relación con intelectuales americanos, a algunos de los cuales conoció en persona en España o durante los años de su "estancia" en Francia.

La relación entre Unamuno y los escritores americanos se trama con visitas, correspondencias, reseñas y artículos que van y vienen de América en movimiento constante a lo largo de los años, llegando a estar intrínsecamente entrelazadas en sus vidas y sus obras, formando una intertextualidad que abarca ambos continentes. $^{25}$

Y este es el contexto que se incardina en lo que Claudio Maíz llama epistolomanía, a cuyo respecto, la referida Virginia Santos, citando a Patricia Arancibia Clavel, habla de unas 20,000 cartas provenientes de todo el mundo, existentes en la Casa-Museo de Unamuno, de las cuales casi la mitad procedían de América. Si bien el autor alemán Hiedermayer $^{26}$ cifra el montón de cartas en 40,000

su padre anécdotas y leyendas derivada de su estancia en Tepic (ver "Mi vista primera de Méjico")... En 1893 redacta Unamuno uno de los primeros estudios serios del Martín Fierro; en el 99, al año de la pérdida del Imperio transatlántico, propone para España la convivencia fraterna con las repúblicas americanas en una comunidad de iguales..." Y así llega el 1904 y con ello la madurez intelectual y religiosa de Unamuno: "Incapaz de reconciliar la fe y la razón, hace de esta incompatibilidad una religión nacional, cuyo Evangelio es el Quijote reinterpretado en este sentido, con una base emotiva en el sentimiento trágico de la vida. Frente a América, Unamuno se fija ahora sobre todo en sus grandes individuos en cuanto figuras trágicas..." Nelson R. Orringer, op. cit.

24 Virginia Santos-Rivero, Unamuno y el sueño colonial, La Casa de la Riqueza, Estudios de Cultura de España, 5, Iberoamericana, 2005.

25 Virginia Santos-Rivero, op. cit.

26 Franz Hiedermayer, Unamuno escribe aly sobre Alemania. Actas del IV Congreso de la Asociación Internacional de Hispanistas, Centro Virtual Cervantes. 
En opinión de la citada Virginia Santos, "las colaboraciones unamunianas en periódicos americanos tienen una faceta práctica inmediata, y es que económicamente representan una conveniente fuente de ingresos que le permiten continuar por una parte su labor filológica como profesor y por otra su labor creativa como autor de novelas, obras de teatro y poesía". Y aclara que esas publicaciones "americanistas" le servían a Unamuno como complemento económico para su sostenimiento y el de su familia. En ese sentido, ya en 1899 , en carta al que después se convertiría en un corresponsal habitual, Pedro Jiménez Ilundain, reconoce: 'No crea Ud. que olvido a América... Empiezo, pues, a tener nombre y mercado en América y a sonar por allí... Gracias a Dios este año ha empezado para mí muy bien, hasta económicamente". ${ }^{27} \mathrm{E}$ insiste con el mismo corresponsal, Pedro Jiménez Ilundain: "Me han pedido un artículo para $\mathrm{La}$ Nación, de Buenos Aires; y hace unos días recibí 150 pesetas como pago; triple de lo que El Imparcial me retribuye. Es una recompensa regular..." ${ }^{28}$ Más adelante le vendría a confesar al mismo corresponsal: "me los pagan tres veces mejor que aquí. Sólo eso me da, con poco trabajo, 240 pesetas al mes. Y mi Quijote se vende..." 29

Y, por último, su labor de crítico literario de literatura americana, que empezó con un ensayo sobre Martín Fierro, en 1894 en la Revista Española, dedicado a Valera, pero donde realizará más o menos esta labor será en la revista La Lectura. Con ese artículo, el joven profesor (tenía 29 años) inicia sus trabajos como crítico literario en Hispanoamérica. Y a este respecto, Ricardo Rojas dejó dicho que: "En España, Miguel de Unamuno, espíritu independiente y genial, nutrido de ciencia eterna, fue de los primeros en proclamar la primacía del cantar indiano" ${ }^{30}$. Reproduce varios textos de Unamuno, "aunque disiente con el carácter acentuadamente español que atribuye al poema”. Parece que no volvió a escribir otra crítica literaria hasta cinco años después, con comentarios al libro Nostalgia de Francisco Soto y Calvo, siendo la última la titulada "Algunas consideraciones sobre la literatura hispanoamericana”, en 1906.

27 Carta 24 de mayo de1899 en Epistolario Americano, 12, p. 63.

28 Carta de 26 de enero de 1900, Ibidem., p. 77.

29 Carta de 4 de mayo de 1907, Ibidem., p. 265.

30 Citado por Antonio Pagés Larraza en "Unamuno y la valoración del Martín Fierro", Centro Virtual Cervantes. 
Resultado de todo ello es que Unamuno llegó a ocupar un lugar estratégico en Hispanoamérica, al lograr difundir sus ideas y particulares visiones desde, sobre todo, las páginas de La Nación de Buenos Aires. Decimos estratégico puesto que el diario argentino se había rodeado de prestigiosas plumas internacionales, dándole un prestigio poco frecuente en la prensa de la época. "Veo con gusto que ha comenzado V. a colaborar en La Nación - le escribe Gómez Carrillo- . Ese periódico influye en toda América pues sus artículos se reproducen en los demás periódicos".

América se convirtió en tema imprescindible para el vasco y, para muchos autores de esa parte del mundo, el maestro, al que se le pide una opinión, un consejo. Y fueron muchos: "Después de una ausencia de más de dos meses en mi tierra, me encuentro a la vuelta con un montón de cartas por contestar y cerca de un metro de folletos y libros, la mitad de ellos argentinos. Y todos piden un juicio, una carta, dirección, consejo..." ${ }^{\prime 1}$

Una carta que le escribió a Matilde B. de Ross, ${ }^{32}$ viuda de uno de sus habituales corresponsales, Luis Ross Múgica, pone de relieve sus deseos de visitar América y, además, describe su reciente obra, Niebla, de "algo corrosivo y acre en que desahogué malos humores y una concepción nada grata de la vida”, y, en especial, expresa su angustia vital y la inevitable finitud de la vida, pero también su ansia, pese a todo, a la inmortalidad.

\section{Influencias americanas}

Así que, dada esa americanidad, obvio hubo de ser que existieran influencias recíprocas, de ida y vuelta: es indudable que Unamuno recibió influjos intelectuales de algunos de los importantes personajes hispanoamericanos y, por otro, resulta indiscutible su ascendencia sobre autores allende los mares. Y entre los que despertaron en Unamuno una especial atención habría que destacar a Sarmiento, Montalvo, Martí, Darío... Pero por razones de espacio me voy a ocupar en exclusivo de las relaciones con el Libertador.

31 Carta a Casimiro González Carrillo, 2 de octubre de 1909. Epistolario Americano, no 175. Ediciones Universidad Salamanca, 1996, p. 333.

32 Carta de 7 de enero de1916, Epistolario Americano, no 249, p. 425, ibidem. 


\section{I. Bolivar-Unamuno}

Según Pedro Rivas, ${ }^{33}$ Unamuno poseía un buen número de obras del Libertador. Nada raro, dada la devoción que sintió por el venezolano. Y esa devoción la manifestaría en sus artículos y ensayos. Ya en 1899 , en un artículo titulado "El pueblo que habla español" ${ }^{4}$ alude que mientras en España se ha luchado siempre contra los hombres, en América:

Nos enseñarán a luchar con la tierra. "Lucharemos con la naturaleza y la venceremos", dijo el gran Bolívar, aquel retoño de la fuerte rama vasca trasplantada a América. Y si el pueblo que luchó con los hombres, el de D. Quijote, hizo el viejo romance castellano, el verbo de la pequeña España en que cantara proezas del Cid y hazañas de conquistadores de hombres, el pueblo que lucha con la naturaleza, el de Bolívar, nos impulsará a hacer la lengua española, el verbo del pueblo que hable español...

De 1921 data el artículo que titula "Don Bartolomé Mitre, español”:

Mitre vio muy claro que "la libertad republicana", que en la América del Sur se desembarazó del yugo del despotismo dinástico de los Borbones asentados en España, era una libertad castizamente española e hija del individualismo ibérico. Sólo que este individualismo aquí, en la vieja España patrimonial, dio ya desde tiempo de los Austrias, de los Habsburgo, el pesimismo quijotesco. Y esto lo sintió el mismo Mitre, republicano y optimista, al encontrarse ante la figura tan quijotesca de Simón Bolívar y tener que encararla. ${ }^{35}$

Diez años más tarde, 29 de marzo de 1931, dicta una conferencia en el Ateneo de Madrid, titulada "Bolívar, el Libertador"36, donde evo-

33 "Unamuno: su visión de América", p. 87.

34 El Sol. Buenos Aires: Repositorio Gredos, Fondo Unamuno, 16 de noviembre de1899.

35 La Nación. Buenos Aires: Repositorio Gredos, Fondo Unamuno, 26 de junio de1921.

36 Archivo del Ateneo de Madrid, Doc. 29 d, 29 de marzo de 1931. 
ca la figura del ilustre venezolano, que al libertar a América trataba también de libertar a España de la Monarquía, señaló que Bolívar no luchó contra España, sino contra el despotismo de Fernando VII, y terminó comparándolo con Don Quijote.

Pero, entre aquel primer artículo de 1899 y esta conferencia en el Ateneo, median sus mejores ensayos sobre el ilustre personaje. Así, su Vida de Don Quijote y Sancho, publicado en 190537; "Don Quijote y Bolívar", publicado en La Nación, Buenos Aires, el 30 de enero de 1907, y "Don Quijote Bolívar"38 y el artículo titulado "San Quijote de la Mancha"39, donde aboga por canonizar a Don Quijote, pero también a Bolívar. El punto de partida pudo haber sido la misma frase de Bolívar, recogida en el ensayo dicho de "Don Quijote Bolívar”y pronunciada por el venezolano casi moribundo: "Acérquese usted, doctor. Se lo diré al oído. Los tres grandísimos majaderos hemos sido Jesucristo, Don Quijote y yo”. Se ponía entre los redentores, nos recuerda Unamuno. ${ }^{40}$ Eso le sugiere a Unamuno que "cuando vuelva yo a hacer otra edición de mi Vida de Don Quijote y Sancho, comentada y explicada, no os quepa duda de que la aumentaré incluyendo en ella pasajes de la vida del Libertador, como incluí pasajes de la vida de Iñigo de Loyola, un vasco representativo". Pero, por lo visto, al final no tuvo tiempo. Mas no por eso dejaría de recordar aquellas palabras del Libertador en un artículo de 1923, titulado "San Quijote de la Mancha":

Dicen que Simón Bolívar — jotro mito! — solía decir que los tres grandes majaderos de la historia habían sido Cristo, Don Quijote y él, Bolívar. Y teniendo en cuenta que majadero es un instrumento para majar, resulta que el dicho, por más que a un cristiano irreverente pueda parecerle irreverente, no está mal, pues ¡cuidado con los que majaron Cristo, Don Quijote y Bolívar! ¡Y con lo que siguen majando! ${ }^{41}$

37 Biblioteca Unamuno, Alianza Editorial, 95, 2009.

38 Grandes Páginas Bolivarianas, Caracas, Casuz.

39 Repertorio Americano (San José de Costa Rica) 19-12-1923, Repositorio Gredos, FMU.

40 Unamuno. Don Quijote Bolivar, p.16.

${ }^{41}$ Unamuno. San Quijote de la Mancha. Repertorio Americano San José de Costa Rica: 10 de diciembre de 1923; Repositorio Gredos, FMU, Artículos 
O sea, que el Libertador considera que su majadería está a la altura de esos personajes inigualables: uno histórico y otro de ficción. Quiero entender al vocablo "majadero" con el significado de "pesado", "incómodo", "impertinente". Y está claro que los tres lo fueron en cantidad suficiente para ser calificados como tales. Jesús vino a redimir a los hombres y, con ello, decir cosas que malsonaban en su época, por lo que fue crucificado. Don Quijote fue también un majadero irredento: denuncia abusos, persigue la injusticia, se rebela contra la tiranía... ¿Y Bolívar? ¡Caramba, menudo majadero! ¡Qué mayor majadería que arrebatar las posesiones coloniales a España, que rebelarse contra la metrópolis!

De todas maneras, esa equiparación intelectual Bolívar-Don Quijote no es propiamente unamuniana, toda vez que Jean Bautista Irvine, agente del gobierno norteamericano, enviado a Venezuela a negociar con Bolívar, en 1818, así lo reconoció. Irvine había sido en Nueva York editor de la revista The Columbian, que en 1816 había publicado una semblanza de Bolívar, redactada en Jamaica, por el general John Robertson. Según nos cuenta Tomás Polanco Alcántara:

Bolívar lo desconcierta. Poco a poco le va cobrando admiración pero no logra entenderlo. Dos veces lo compara con Don Quijote. La primera vez, en una nota para el Secretario de Estado informativa de cierta reunión del Libertador con los jefes militares a quienes hizo una larga exposición: "Parecía un Quijote con ambición militar". La otra, en una carta para el Dr. S. D. Forsyth, con quien entonces mantenía buenas relaciones, le comenta que Bolívar tiene una inextinguible imaginación parecida a la de Don Quijote para crear castillos, flotillas, jefes fuertes, bloqueos, líneas de circunvalación, que nunca existieron. ${ }^{42}$

Y parece ser que el mismo Bolívar no quiere desacreditar a quienes le comparan con la figura del Quijote, pues es sabido que, no sólo en su vida privada, sino incluso en la pública y en sus discursos, traía a colación con bastante frecuencia a Don Quijote. De esto nos

de Miguel de Unamuno, CMU-8-341.

42 Simón Bolivar: Ensayo de una interpretación biográfica a través de sus documentos. Mérida, Venezuela: Universidad de los Andes, Biblioteca digital andina. 
habla Roxana Gardés de Fernández, ${ }^{43}$ al exponer múltiples alusiones directas o indirectas del Libertador hacia Don Quijote.

Unamuno, al principiar el segundo de los artículos, nos pone sobre aviso de que lo que le interesa en especial de Bolívar es el hombre: "Bolívar fue un hombre, todo un hombre; un hombre entero y verdadero, y ser todo un hombre es más, mucho más que ser $U e$ bermensch, una mera abstracción nietzscheana, de los que quieren y presumen, pero no logran". Estas afirmaciones venían a corroborar aquellas otras del primero de los ensayos, "Don Quijote Bolívar": "Ante todo, los hombres. Siempre me ha interesado más el individuo que las muchedumbres, las biografías más que las historias" ${ }^{4} 4$ Para a continuación añadir que "Bolívar era de la estirpe de Don Quijote, el de los bigotes, negros y grandes". Y luego, al tomar unas palabras de Perú de Lacroix en su Diario de Bucaramanga, confirma que el Libertador tenía "la frente alta, pero no muy ancha, y surcada de arrugas desde temprana edad; pobladas y bien formadas cejas; los pómulos salientes; las mejillas hundidas...” Además,

tenía el pecho angosto, el cuerpo delgado, las piernas sobre todo... La semejanza aumenta cuando se le ponía al Don Quijote americano el rostro ceñudo, manifestando pesadumbre, pensamientos tristes e ideas sombrías. Sólo que el Libertador, que tenía las patillas y el mostacho tirando a rubio, no usaba en sus últimos años bigotes, mientras que los de Don Quijote eran grandes, negros y caídos.

Con ello, el bilbaíno ya hace una primera aproximación de Bolívar con el Quijote: la fisonómica.

El segundo rasgo que le interesa de Bolívar es el Bolívar héroe. $\mathrm{Y}$ entonces nos tenemos que remitir a una de sus principales obras, Del sentimiento trágico de la vida, en cuyo apartado último, "Conclusión", afirma que "adonde hemos de ir a buscar el héroe de nuestro pensamiento no es a ningún filósofo que viviera en carne y hueso, sino a un ente de ficción y de acción, más real que los filó-

43 "El Quijote en el Ideario de la Independencia Americana. Recepción y Símbolo". Argentina: Universidad Nacional de Misiones, Actas IV, Centro Virtual Cervantes, 1996.

44 Unamuno. Don Quijote y Bolivar, p. 68. 
sofos todos; es a Don Quijote”. Así que Unamuno ve en Bolívar al héroe, tal y como lo fue el Ingenioso Hidalgo.

Un héroe para un poema a la manera de los Browning, en que toma un personaje histórico como centro de reflexiones poéticas. Es, sin duda, Simón Bolívar, un héroe para un poema a la manera de los Browning... Cuando me pongo a escribir estas líneas sobre Bolívar, uno de los más grandes y más representativos genios hispánicos... ${ }^{45}$

Y un héroe necesita otro héroe en que fijarse: Napoleón. Para nuestro autor, "es innegable la fascinación que Napoleón ejerciera sobre Bolívar...Y la ejerció más cuando más quiso apartarse de sus malos ejemplos. Cabe decir, sin exceso de paradoja, que nunca trasuntó más Bolívar a Napoleón que cuando se esforzó por no imitarle". ${ }^{6}$ $\mathrm{Y}$ añade que "el napoleonismo de Bolívar es evidente y en nada amengua su grandeza, más bien la engrandece. Sólo los grandes, los genios, los héroes alcanzan a los grandes, los genios y los héroes... Cierto que fue menos egotista, más humano que Napoleón...” De ahí que no sea extraño que esa fascinación que sentía por el emperador francés se acrecentara cuando asistió a la coronación de éste en París, el 2 de diciembre de $1804 .^{47}$

El tercer rasgo puede ser el españolismo de Bolívar. ¿Quién mejor que Don Quijote para representar al español? Es evidente que el que se acerca a la obra de Cervantes sabe que se trata de la mejor obra de la literatura española (y, por supuesto, una de las primeras de la literatura universal) y que el Ingenioso Hidalgo representa a un español (no podría ser alemán o inglés) y, claro, Bolívar no podría asemejarse a un alemán o inglés, sino a un español. Lo cual coincide con la descripción que recoge Unamuno, que hace Gil Fortoul, en

45 Unamuno. “Don Quijote y Bolívar”, p. 68.

46 Ibidem., p. 7.

47 "Yo ponía toda mi atención en Napoleón, y sólo a él veía entre toda aquella multitud de hombres que había allí reunidos; mi curiosidad no podía saciarse y aseguro que entonces estaba muy lejos de prever que un día sería yo también el objeto de atención, o si se quiere, de la curiosidad de casi todo un continente y puede decirse también del mundo entero..." Diario de Bucaramanga. 
su Historia constitucional de Venezuela: "En suma, tipo vascongado, de que descendía por línea paterna..." Y añade:

Si su organismo era sobre todo español, los ímpetus de su alma también lo fueron a menudo...Y tengo que decir de Bolívar lo que de Sarmiento he dicho y repetido, y es que nunca se me aparece más español que cuando habla o parece hablar mal de España ¡en español! No. Don Quijote nunca puede hablar mal de España, aunque maldiga de los españoles. ${ }^{48}$

Y añade que "su estilo mismo, el de Bolívar, era un estilo quijotesco, algo enfático, muy español, entre gongorino y conceptuoso, aunque con evidente influencia de los escritores franceses de fines del siglo XVIII". Y concluye su ensayo, "Don Quijote Bolívar”, reafirmando su españolidad y la de Bolívar, Martí y Rizal: "Y gracias a Dios que hemos llegado a tiempos en que un español, sin renegar de su españolidad, sino más bien afirmándola más aún, puede rendir culto, y culto patriótico, de la gran patria, lo mismo que a ese colosal Bolívar, a un Martí, a un Rizal”.

Todavía en 1920, Unamuno publica un artículo titulado "La raza y la guerra civil” ${ }^{49}$, donde hace alusión, de nuevo, a esa condición española de Bolívar:

Refiriéndose a la guerra por la independencia de Venezuela, a la que dirigió el gran venezolano y grandísimo español Simón Bolívar, una de las más grandes y más universales figuras de nuestra común raza española. Porque Bolívar, de apellido vasco, de sangre... ¿quién sabe?, de nacimiento caraqueño, aprendió a pensar y a sentir y a querer — porque se siente y se quiere con lenguajeen español.

El cuarto rasgo característico común entre los dos personajes, puesto de relieve por el bilbaíno, fue el que ambos se movían "sin blanca”, esto es, sin dinero: Don Quijote no llevaba consigo blanca, ni se preocupaba de ello, porque "él nunca había leído en las historias de los caballeros andantes que ninguno las hubiese traído", mien-

48 Unamuno. “Don Quijote Bolívar”, p. 12.

49 El Liberal. Madrid: 15 de julio de 1920. 
tras que Bolívar llegó a afirmar que: "yo no quiero saber lo que se gasta en mi casa”. Y alude Unamuno que no tenía un duro (Bolívar) pero derrochaba de tremenda manera o daba libertad a cientos de esclavos que le representaban mucho dinero, o renunciaba a los "millones en metálico que representaba la gratitud de los pueblos que él libertaba. Y, claro, para renunciar a millones, en pleno siglo XIX, 'se necesita ser un Don Quijote de buena ley, genuino"'.

El quinto rasgo común a juicio de Unamuno es lo que él llama fe quijotesca. Don Quijote, después de liberar a unos galeotes en Sierra Morena (cap. XXII), es apedreado y robado por aquellos mismos a los que había dado la libertad. Y ante semejante situación, el Caballero de la Triste Figura le dice a su escudero: "Siempre Sancho, lo he oído decir: que el hacer bien a villanos es echar agua al mar". Es lo que los latinos llamaban mari aquam addere, o sea, lo desaconsejable de hacer bien a quien no lo agradece. Pues algo semejante, nos dice Unamuno, le ocurrió a Bolívar. "Insultado, calumniado, atropellado, proscrito por aquellos mismos pueblos que libertara, exclamó: he arado en el mar" ${ }^{50}$. Y califica tal actitud como de fe quijotesca. ${ }^{51}$ Que se puede relacionar con la actitud quijotesca que tuvo Bolívar a raíz del terremoto de Caracas, el 26 de marzo de 1812, el cual, al desenvainar la espada..., gritó: ¡Si se opone la naturaleza, lucharemos contra ella y haremos que nos obedezca! ${ }^{52}$

Don Miguel de Unamuno apunta que ambos personajes cabalgaban solos, con lo que entramos con el sexto rasgo común. Es decir, que hablamos de dos personajes solitarios. Por un lado, la soledad del Ingenioso Hidalgo no pasa desapercibida. Encarna el individualismo, él solo pretende luchar contra las injusticias del mundo, Sancho es sólo su escudero. Además, y por eso, los caballeros cabalgan solos. ${ }^{53}$

50 "He arado en el mar y sembrado en el viento", Simón Bolívar. Se dice que la pronunció después de que su Gran Colombia se dividió y dejó de existir.

51 Unamuno. Don Quijote Bolivar, p. 14.

$52 \mathrm{Al}$ respecto de esa frase, se dice que fue tergiversada, en 1829 , por José Domingo Díaz, que vivía en España, se afirma que lo realmente dicho por el Libertador fue: "Aunque la naturaleza se oponga lucharemos contra ellos (en referencia a españoles y realistas) y haremos que nos obedezcan”. Néstor Paralta Rojas. El Nacional. 29 de octubre de 2000.

53 José Pascual Buxó. "La soledad de Don Quijote" en Revista de Estudios Cervantinos, núm. 5. 2008. 
En cuanto a Bolívar, Unamuno refiere que "él hizo la guerra puede decirse que solo, sin Estado Mayor, a lo Don Quijote. La humanidad que le seguía — humanidad y no mero ejército- era su Sancho". ${ }^{44}$

¿Bolívar un ser solitario? Se suele decir de él que era un solitario que se dedicó a la empresa de la libertad. A esa pregunta, responde de manera afirmativa Fermín Goñi cuando dice que:

un ser solitario y pocas fueron las personas que podían decir que fueron cercanas o amigas, como el General Sucre, quien muere muy joven, y esa soledad también tuvo que ver con su final, con esa angustia de estar luchando por unos pocos compatriotas, que en buena parte de ellos no le querían, y si pudieran, querían que desapareciera, porque muchos pensaban que él quería ser supremo, el cacique o el rey. ${ }^{55}$

El séptimo rasgo para el filósofo y novelista español fue la locura en que, en mayor o menor medida, ambos personajes se ven envueltos: Unamuno afirma que lo que condujo a Don Quijote a "esa locura caballeresca" fue "aquel amor tímido y contenido hacia Aldonza Lorenzo, aunque en realidad es bien sabido que lo que llevó al Ingenioso Hidalgo a perder la razón fue la lectura irrefrenable de libros de caballerías, que lo hizo creerse un caballero andante". Pero sí es cierto que Don Quijote anduvo todo el tiempo en su búsqueda; de una forma u otra, Don Quijote, en su locura, se sentía atraído por esa dama y al no tenerla, al paso de los días y meses, claro, su locura se acrecentaría. Unamuno equipara esa locura quijotesca con la que sufrió Bolívar por la muerte de su mujer, María Teresa.

La muerte de su joven compañera (dulce y melancólica figura que la historia deja en indecisa penumbra) — dice el señor Gil Fortoul- le arroja al punto en un verdadero torbellino: viajes que duran tres años; al principio, la nostalgia del primer amor, nostalgia que a veces se convierte en desesperación; proyectos confusos; al fin, el alto ideal que se apodera de su espíritu arrastrándolo a la lucha por la libertad de la patria.

54 Unamuno. Don Quijote Bolivar, p. 4.

55 Fermín Goñi, en una entrevista a La Patria, 14 de septiembre de 2014. 
Agrega el señor Gil Fortoul que fue tal la impresión dolorosa con que acariciaba el recuerdo de su mujer "que llegó hasta desear sinceramente la muerte". Y he aquí que

aquella María Teresa Rodríguez, a quien conoció y con quien se casó en España —a Bilbao, mi pueblo, fue a verla en el otoño de 1891-; esa dulce figura penumbrosa que desfila por la historia, fue la Aldonza Lorenzo de aquel Quijote americano, y cómo muerta ella se le convirtió en Dulcinea, en la Gloria. ${ }^{56}$

Octavo rasgo: amor a la ambición, a la gloria.

Don Quijote soy y mi profesión la de andante caballería. Son mis leyes el deshacer entuertos, prodigar el bien y evitar el mal. Huyo de la vida regalada, de la ambición y de la hipocresía. Y busco para mi propia gloria la senda más angosta y difícil. ¿Es eso de tonto y mentecato ? $^{57}$

La ambición de Bolívar era liberar la América española. Y al referirse a Napoleón señaló lo siguiente: "como él quiero hacerme emperador o rey, dominar la América del Sur como ha dominado él la Europa..."

Unamuno tercia y nos dice que "el quijotesco amor a la gloria, la ambición, la verdadera ambición, no la codicia, no la vanidad del pedante, no el deseo de obtener pasajeros aplausos como un histrión, sino la alta ambición quijotesca de dejar fama perdurable y honrada”, le movía. Lo reconocía él mismo.

"Yo vivo de la estimación de los hombres", escribía en 1829 a Sir Robert Wilson, apesadumbrado ante las calumnias y los ataques de que estaba siendo víctima, y según los cuales aspiraba a la tiranía.... Bolívar se preocupaba de lo que de él dijera la historia, como los héroes homéricos y como también los condenados dantescos. ${ }^{58}$

56 Unamuno. Don Quijote y Bolivar, p. 71.

57 Cervantes. El Ingenioso Hidalgo Don Quijote. Editorial Burgos, 1961.

58 Unamuno. Don Quijote Bolivar, p. 8. 
El siguiente elemento común será la representación de la inmortalidad. Este tema ocupa con certeza un lugar central en el pensamiento del bilbaíno y sobre ella giran los temas esenciales de su obra. Ante el descubrimiento de su finitud, nos dice, que es la tragedia del ser humano, el hombre se aferra a la esperanza y reivindica el derecho a no morir del todo. No olvidemos, por ejemplo, Niebla, una de sus mejores novelas, donde el protagonista, sabiendo que va a morir, de forma inusitada se presenta en el despacho del autor (Unamuno) y le dice que no quiere morir. Es decir, Unamuno contempla la inmortalidad como el fin del hombre de carne y hueso, aquel que se sabe finito pero lucha contra esa finitud, porque quiere sobrevivir. Pues he aquí que, para Unamuno, Don Quijote es el prototipo del hambre de inmortalidad. En la Vida de Don Quijote y Sancho, Unamuno glosa (casi capítulo por capítulo) la novela del Ingenioso Hidalgo. En sus comentarios aparece la figura de Don Quijote como una resultante combinada de su filosofía del hambre de inmortalidad, de cristianismo, de heroísmo y locura. Y, por poco que lo diga o haya dicho Unamuno, está claro que la figura de Don Quijote es en absoluto inmortal. Como lo es la de Simón Bolívar: de esos dos majaderos nunca la historia se olvidará. Y Unamuno, al referirse al Libertador, habla de esa inmortalidad, en la parte final de su ensayo "Don Quijote Bolívar", "que su intención ha sido mostrar al Hombre español, al Quijote de la América hispana libertada, a uno de los más grandes héroes en que ha encarnado el alma inmortal de la Hispania máxima”. Pero antes había dicho que: "era un hombre; era el Hombre encarnado. Tenía un alma y su alma era de todos y su alma creó patrias y enriqueció el alma española, el alma eterna de la España inmortal y de la humanidad con ella."

El rasgo siguiente podría ser la angustia. Don Quijote ha sido calificado como el Caballero de la Angustia ${ }^{59}$, el cual,

lanzado por fuerzas inescrutables hacia la vida sólo podrá domeñarla o evadirla, dominio o evasión a los que cada espíritu dará la mezquindad o la grandeza de sí mismo. En el golpear de la vida la personalidad se expande o se contrae, brota a la luz o se enraíza en la sombra; y el hombre vive, en consecuencias, a tono con la reali-

59 Otto Olivera. Don Quijote, el caballero de la angustia. Syracuse University, Hispania, 1961. 
dad un hostil a ella, a satisfacción o a disgusto, que es como decir en acatamiento o en rebeldía... Como medio de reacción al contacto infeliz con el medio, el hombre Alonso Quijano se repliega y concentra en sus facultades meramente imaginativas que, como único refugio en la evasión de lo cotidiano, acaban por normar toda su vida. Los libros de caballería se tornan escuela de la fantasía...

Unamuno se refiere a la angustia del Libertador, cuando recuerda una carta de éste al Marqués del Toro, en la que señala aquello de que "mis tristezas vienen de mi filosofía", lo que lleva a Unamuno a preguntarse si "llegaría Bolívar a sentir la angustia metafísica de todos los grandes, la terrible voz que surge del silencio de las eternas tinieblas y nos dice: y todo para qué" ${ }^{60}$

La socióloga peruana Linda Lema Tucker habla de la angustia que sintió Bolívar aquella mañana del 15 de agosto de 1805, en el Monte Sacro de Roma:

De pronto, la exaltación acumulada durante los días anteriores en el corazón de Bolívar y la angustia que le produjo el recuerdo de su país natal explotaron violentamente. Con los ojos encendidos como dos llamas, se puso en pie, se cogió con ímpetu a las manos de Rodríguez, cayó de rodillas y dio rienda suelta a sus pensamientos, con una emoción incontenible dijo: Juro delante de usted; juro por el Dios de mis padres; juro por ellos; juro por mi honor, y juro por la patria, que no daré descanso a mi brazo ni reposo a mi alma, hasta que haya roto las cadenas que nos oprimen por voluntad del poder español. ${ }^{61}$

¿Y qué hay del sentido de justicia?

Cervantes nos dice que la misión del Ingenioso Hidalgo es: "deshacer agravios, enderezar entuertos, enmendar sinrazones, mejorar abusos y satisfacer deudas”. De ahí que Don Quijote se echa a los caminos para cumplir la justicia que ve perdida en el mundo. Y en este sentido, Unamuno escribe que:

60 Unamuno. Don Quijote y Bolivar, p. 8.

${ }^{61}$ Linda Lema Tucker, Simón Bolivar y el juramento del Monte Sacro, ALAI, América en Movimiento, 14-8-2014. 
Don Quijote castigaba, es cierto; pero castigaba como castigan Dios y la Naturaleza, inmediatamente, cual es naturalísima consecuencia del pecado. Así castigó a los arrieros que fueron a tocar sus armas cuando las velaba, alzando la lanza a dos manos, dándoles con ella en la cabeza y derribándolos para tornar a pasearse con el mismo reposo que primero, sin cuidarse más de ellos; así amenazó a Juan Haldudo el rico, pero soltándole bajo su palabra de pagar a Andrés; así arremetió a los mercaderes toledanos, no bien los oyó blasfemar contra Dulcinea... Su justicia era rápida y ejecutiva; sentencia y castigo eran para él una misma cosa; conseguido enderezar el entuerto, no se ensañaba en el culpable. Y a nadie intentó esclavizar nunca. ${ }^{62}$

Pues Bolívar era igual, nos dice.

Fusiló a propios y extraños, pero jamás con ensañamiento. Su justicia, como la de Don Quijote, era rápida y ejecutiva. Boves lo derrota en La Puerta, y hace una carnicería de las suyas: Bolívar fusila inmediatamente ochocientos prisioneros; Piar, su teniente, se insubordina, huye del ejército...: Bolívar lo hace aprehender, juzgar y fusilar. Lo propio hizo con Berindoaga... Lo mismo con Vanoni... ${ }^{63}$

Otro rasgo común que les reconoce Unamuno es el ser teatrales y enfáticos: 'No, Bolívar no fue nunca pedante, nunca doctor, nunca catedrático. Fue teatral y enfático, cierto es, como Don Quijote, como su casta española... " 64

Pero he aquí que también en los últimos momentos de sus respectivas vidas tuvieron sus coincidencias:

1) Calenturas: tanto Bolívar como Don Quijote mueren con calenturas.

El Libertador llegó a la ciudad de Santa Marta, Colombia, ya enfermo, el día 1 de diciembre (estamos en 1830), como nos cuenta el médico que le asistió, don Alejandro Próspero Reverend, "la

62 Unamun. Vida de Don Quijote y Sancho, p.115.

${ }^{6}$ Unamuno. Don Quijote Bolivar, p. 13.

64 Unamuno. ibidem, p. 4. 
enfermedad de S. E. me pareció ser de las más graves y mi primera opinión fue que tenía los pulmones dañados" (Boletín núm. 1. $1^{\circ}$ de diciembre). En el Boletín siguiente opina que "la enfermedad era un catarro pulmonar crónico”. Tiene una ligera mejoría, pero el día 8 recae: "La calentura le dio con más fuerza..." El día 11 (Boletín núm. 13) "a media noche le entró la calentura con más fuerza...” Y de esta manera fue empeorando hasta fallecer a la una del día, cuando se certificó que El Libertador había fallecido por tisis tuberculosa. ${ }^{65} \mathrm{O}$ sea, que Simón Bolívar falleció preso de altas temperaturas, calenturas, claro, derivadas de la tuberculosis. Don Alonso Quijano, por su parte, falleció al padecer altas calenturas, como nos relata Don Miguel de Cervantes en su grandiosa obra. ${ }^{66}$

Fernando Rielo, en su obra Teoría del Quijote" causa de la muerte que Cervantes atribuye a Don Quijote... fue, en verdad, la melancolía”. No lo discutimos. La melancolía puede conducir a la depresión y ésta es fácil que se transmute en cualquier enfermedad somática. Pero lo que está claro es que el autor, Cervantes, nos dice que tenía calenturas, o sea, altas fiebres. Eso no lo podemos ni debemos discutir.

2) Confesión: ambos personajes antes de morir son confesados por el rito católico.

El médico de cabecera de sus últimos momentos, doctor Alejandro Próspero, relata que en aquellos últimos días, por recomendación del general Montilla, fue llamado el obispo de Santa Marta, que estuvo en conferencia con el ilustre enfermo, del cual se dice que dijo:

¿Qué es esto, estaré tan malo para que se me hable de testamento y de confesarme?... El cura de la aldea de Mamatoco, cerca de San Pedro, acompañado de sus acólitos y unos pobres indígenas, vino de noche a pie, llevando el viático a Simón Bolívar. ¡Qué contraste! Un humilde sacerdote y de casita ínfima a quien realzaba sólo su carácter de ministro de Dios, sin séquito y aparatos pomposos propios a la ceremonias de la Iglesia, llegase con los consuelos de

65 Alejandro Próspero Reverend. La última enfermedad. Los últimos momentos de vida del Libertador. Bucaramanga: Colección Bicentenario, 2008.

66 Cervantes, op. cit., p. 322.

67 Fernando Rielo. Teoría del Quijote. Madrid: Ediciones Porrúa, 1982. 
la religión al primer hombre de Sur América, al Ilustre Libertador y Fundador de Colombia ${ }^{68}$

Es decir, que confesó antes de irse de este mundo. Eso fue el día 31 de diciembre de 1830. Pero el día 18, según nos cuenta su médico de cabecera, el doctor Próspero Reverend, el Libertador oyó misa en el coro: "Esta mañana asistimos todos a misa con el Libertador, que desde la víspera había mandado a decir al cura que le hiciera preparar el Coro para él y su comitiva: allí estuvimos solos, bien desahogados y con muchos menos calor que el que habíamos sufrido en la Iglesia”. ${ }^{69}$

En cuanto a Don Quijote, don Miguel de Cervantes nos cuenta que Alonso Quijano fue asistido en sus últimos momentos por un cura:

Los de hasta aquí —replicó don Quijote—, que han sido verdaderos en mi daño, los ha de volver mi muerte, con ayuda del cielo, en mi provecho. Yo, señores, siento que me voy muriendo a toda prisa: déjense burlas aparte y tráiganme un confesor que me confiese y un escribano que haga mi testamento, que en tales trances como este no se ha de burlar el hombre con el alma; y, así, suplico que en tanto que el señor cura me confiesa vayan por el escribano... Hizo salir la gente el cura, y quedóse solo con él y confesóle... Acabóse la confesión y salió el cura diciendo: Verdaderamente se muere y verdaderamente está cuerdo Alonso Quijano el Bueno; bien podemos entrar para que haga su testamento. ${ }^{70}$

3) Muertes en la cama: los dos se despiden de este mundo en la cama.

El Libertador, prácticamente todo el mes de diciembre, 1830, su último mes en la Tierra, lo pasó en la cama: "A las doce empezó el ronquido, y a la una en punto expiró el excelentísimo señor Libertador, después de una agonía larga pero tranquila"71. Terminó de dictar sus últimas voluntades.

68 Alejandro Próspero Reverend, op. cit, pp. 222-223.

69 Ibidem, p. 109.

70 Cervantes, op. cit., cap. LXXIIII.

71 Alejandro Próspero Reverend, op. cit, Boletín número 33. 
En fin, llegó el último de don Quijote, después de recibidos todos los sacramentos, y después de haber abominado con muchas y eficaces razones de los libros de caballería. Hallóse el escribano presente, y dijo que nunca había leído en ningún libro de caballería que algún caballero andante hubiese muerto en su lecho tan sosegadamente y tan cristiano como don Quijote; el cual, entre compasiones y lágrimas de los que allí se hallaron, dio su espíritu: quiero decir que se murió. ${ }^{72}$

Y para finalizar, me permito reseñar que tanta fue la admiración del insigne vasco por esos dos personajes, Bolívar y Don Quijote, que acabó por parecérseles. Veamos:

\section{La majadería}

Unamuno, sin duda, fue un ilustre majadero, a la altura, por lo menos de aquellos dos grandes majaderos, en el panorama español de principios del siglo XX. Siempre iba a contracorriente. Mientras los que se llamaban progresistas pensaban que había que europeizar España, él decía que había que españolizar Europa. Cuando la mayor parte de España pretendía continuar en Cuba, Unamuno mostraba sus simpatías con la independencia de la isla. Todos hablan de novelas, Unamuno les llama "nivolas". O sea, un majadero integral.

\section{La españolidad}

Unamuno era español y se sentía sobre todo español, siendo vasco. ¡Soy español!, español de nacimiento, de educación, de cuerpo, de lengua y hasta de profesión y oficio: ¡Español sobre todo y ante todo!, había proclamado. Y hemos visto que consideraba a Bolívar españolísimo; sin que tengamos nada que decir de la mayor representación española de todos los tiempos: el Quijote.

3. La situación de estar constantemente "sin blanca"

Los dos personajes estudiados se conducían en la vida sin portar dinero, "sin blanca". De Unamuno, se sabe que en una época

72 Cervantes, op. cit., cap. último. 
las pasó canutas, muchas bocas que alimentar y pocas entradas. Y ése fue el motivo principal de escribir tantos artículos en la prensa extranjera y su pretendida idea de emigrar a Argentina.

4. La fe quijotesca: el "hacer bien a villanos es echar agua al mar" (El Quijote), y "he arado en el mar", de Bolívar.

Si entendemos por ella el ansia de vida eterna, además de búsqueda de fama y gloria, ${ }^{73}$ podemos afirmar que, al igual que don Quijote y Bolívar, Unamuno era portador de fe quijotesca. Le sacaba de quicio la finitud de la vida, del hombre, y entonces luchaba (y esa era su agonía) por sobrevivir. Él quería ser inmortal.

\section{La implacable soledad}

Don Quijote era el Caballero de la Triste Figura. Cabalgaba solo, Sancho era otra cosa, muy importante, pero otra cosa. Bolívar, nos dice Unamuno, que hizo la guerra "puede decirse que solo, sin Estado Mayor, a lo don Quijote”. Es más, se sabe que incluso carecía de amigos, salvo el general Sucre.

Unamuno, al igual que sus héroes, era él solo: ni un partido, ni una asociación, secta o religión. Él solo. Solo cuando se enfrenta a la jerarquía política, y militar. Y también solo cuando el obispo Pildain lo tachó de hereje, aunque fuere a título póstumo. $^{74}$

\section{Personalidad angustiosa}

En don Quijote no es difícil encontrar la angustia, no en vano ha sido calificado como el Caballero de la Angustia, como ya dije; de la angustia de Bolívar hace referencia el mismo Una-

73 "La fe quijotesca unamuniana no se reduce, pues, como algunos unamunistas la interpretan, a la búsqueda de fe y gloria terrena, aunque ciertamente ambas están muy presentes tanto en el Quijote unamuniano como en el cervantino. Sin embargo, por encima de ellas, a través de ellas, Unamuno expresa las ansias que hay en el ser humano, en particular en él mismo, de vida eterna”. Rogelio García Mateo, Don Quijote de la Mancha e Iñigo de Loyola en Unamuno según la "Vida de Don Quijote y Sancho". Actas Cervantinas, VIII, Centro Virtual Cervantes.

74 Pildain, Obispo de Canarias, 19-9-1953, dicta una Carta Pastoral desaconsejando la lectura de una de las principales obras de Unamuno. 
muno, al citar una frase del Libertador en una carta de 1824 al marqués de Toro, y también la que refiere la socióloga Linda Lema Tucker, que - dice- sufrió Bolívar en el Monte Sacro, en la mañana del 15 de agosto de 1805 . Por su parte, González Caminero hace referencia a la angustia que experimentó Unamuno en la cumbre de la Peña de Francia. ${ }^{75}$

7. La presencia de Dios

Vimos que Simón Bolívar se confesó antes de morir. don Quijote también fue asistido por un cura. Unamuno, por razones obvias, dimanantes de su situación personal con la religión católica, no fue asistido por un sacerdote, pero sí murió pronunciando el nombre de Dios: “¡Dios no puede volverle la espalda a España!"76

8. Muertes alejadas del talante de un caballero

Para Sancho, el fiel escudero, el buen caballero debe morir en la batalla, peleando, por tanto ninguno de los tres murieron de forma caballerosa. Aunque se podría decir que Unamuno sí que murió como un caballero, batallando, o, por lo menos, vociferando.

9. La locura

Hemos visto que la locura fue un rasgo común en Bolívar y don Quijote. don Miguel de Unamuno, si no locura, sí que tuvo ideas suicidas, que él mismo nos narra en su Diario intimo.

\section{El amor}

Los tres tuvieron su amor y los tres fueron fieles a sus amores respectivos. don Quijote con su Dulcinea; el Libertador con su esposa, doña María Teresa Rodríguez del Toro, y Unamuno con su querida Concha Lizárraga, fallecida en 1934. A ninguno de los tres se les conoce otro amor.

${ }^{75}$ Nemesio González Caminero, ibidem.

${ }^{76}$ Luciano Egido. Agonizar en Salamanca, ibidem. 


\section{Conclusiones}

Sentado todo lo anterior, me atrevo a formular como primera conclusión el hecho de que a Unamuno no se le puede entender de forma completa sin contar con su faceta americana. Es más, debemos considerarle el intelectual español más volcado en Hispanoamérica, durante finales del siglo XIX y el primer tercio del XX, y, de manera recíproca, el más respetado desde la otra orilla.

En segundo lugar, si bien sintió fascinación por otros grandes personajes americanos, léase Sarmiento. Montalvo y Martí, fue por Bolívar su auténtica devoción, al emparejarlo incluso con don Quijote, el héroe español por antonomasia y el héroe de su propia filosofía.

Y, por último, reseñar el parecido, no intencional, entre el mismo Unamuno con los otros dos grandes personajes históricos, el uno ficticio y el otro real como la vida misma: don Quijote y Simón Bolívar.

\section{Bibliografía}

\section{Básica}

Unamuno, Miguel de. "De patriotismo espiritual”, artículos en: $L a$ Nación. Buenos Aires: 1901-1914. Edición y notas Victor Quimette, Ediciones U. Salamanca, 1997.

- Epistolario Americano. Edición de Laureano Robles, Universidad de Salamanca, 2004.

- Epistolario. Cuadernos Cátedra U. Dialnet, 2000.

Miguel de Unamuno. Americanidad. Venezuela: Colección "La expresión americana", Biblioteca Ayacucho, 2002.

. Don Quijote y Bolivar: a propósito de una historia de Venezuela. Buenos Aires: Repositorio Gredos, U. Salamanca, Fondo Unamuno, 15 de mayo de 1907.

cas: Casuz Ediciones, 196.

\section{Complementaria}

Baquero, Gustavo. La América de Unamuno. Biblioteca Virtual Cervantes, 2010.

Buxó, José Pascual. "La soledad de Don Quijote”. Revista de Estu- 
dios Cevantinos, 5, 2008.

Cervantes, Miguel de. El Ingenioso Hidalgo Don Quijote de la Mancha. Editorial Burgos, 1961.

Chaves, Julio César. Unamuno y América. Madrid: Editorial Cultura Hispánica, 1964.

Egido, Luciano G. Agonizar en Salamanca. Tusquets, 2006.

González Caminero, Nemesio. Unamuno y Ortega. Publicaciones de la Universidad Pontificia Comillas, 1987.

Gordo Piñar, Gemma. Miguel de Unamuno y México. Relación y Recepción. Tesis doctoral. Madid: Año 2013.

Goñi, Fermín. La Patria. 14 de septiembre de 2014.

Hiedermayer, Franz. Unamuno escribe aly sobre Alemania. Actas del IV Congreso de la Asociación Internacional de Hispanistas, Centro Virtual Cervantes.

Lema Tucker, Linda. Simón Bolivar y el juramento del Monte Sacro, ALAI, América en Movimiento. 14 de agosto de 2014.

Maíz, Claudio, De París a Salamanca, Salamanca: Ediciones Universidad, 25, 2004.

Morales Padrón, Francisco. "La imagen de Hispanoamérica en la España de los siglos XIX y XX” en Estudios Latinoamericanos, 6, 1980 .

Olivera, Otto. Don Quijote, el caballero de la angustia. Syracuse Unversity, Hispania, 1962.

Orringer, Nelson R. Presentación. "Unamuno y la 'Americanidad'”. Universidad de Conecticut, Colección "La Expresión Americana”, 24, 2012.

Pagés Larraza, Antonio. Unamuno y la valoración del Martín Fierro. Centro Virtual Cervantes.

Próspero Reverend, Alejandro. La última enfermedad. Los últimos momentos de vida del Libertador. Colección Bicentenario. Bucaramanga, 2008.

Rivas, Pedro. Unamuno: Su visión de América. Formas de Hispanidad. CEPI, 2012.

Savater, Fernando. Prólogo a Del sentimiento trágico de la vida. Biblioteca UNAM. Alianza Ed. 2008.

Santos-Rivero, Virginia. Unamuno y el sueño colonial. La Casa de la Riqueza, Estudios de Cultura de España, 5. 